\title{
A Critical Analysis of the Selection Criteria of Expert Teachers in ELT
}

\author{
Ramin Akbari \\ Tarbiat Modares University of Tehran, Iran \\ Elham Yazdanmehr (Corresponding author) \\ Tarbiat Modares University of Tehran, Iran
}

\begin{abstract}
So far, in the early years of the twenty-first century, expertise studies have been undertaken in a large number of domains. Applied linguistics is relatively a newcomer to the list which makes any study aiming to cast light on some aspect of expertise in this domain worth considering. Currently, English language expert teachers are selected according to a set of common general criteria of expertise and/or national standards. The present study casts a critical look at the most commonly used selection criteria of expert teachers including years of working experience, social/professional recognition, rewards and recommendations from school, learners' achievement, normative- or criterion-based performance indicators. It also critically addresses the perceivably most comprehensive national standards of teaching English including those of England and the U.S. Subsequently, it draws attention to the need for providing a reliable and comprehensive operational definition for teacher expertise in the realm of English Language Teaching (ELT) and discusses its possibility and quality of design.
\end{abstract}

Index Terms - expert teacher, selection criteria, ELT

\section{INTRODUCTION}

The arena of education is currently under the effect of an international drive that focuses on uncompromising learner assessment, considering only instructors and schools responsible for academic performance of pupils. One consequence of these reform endeavors has been an increased emphasis on teacher quality and teacher evaluation (Dwyer \& Stufflebeam, 1996). Recent reports in the U.S. found out that a highly significant way of enhancing students' academic achievement, for a society, is to promote teacher's efficiency (The American Council on Education, 1999; NCTAF, 2003). Following the significance of teacher efficiency, the No Child Left Behind Act set some criteria according to which by the 2005-6 instructional year all learners were to encounter truly efficient teachers of basic school courses. The determinant of teacher efficiency, nevertheless, continues to be a growing subject, both for educational decision makers (Education Trust, 2003), and those interested in the related research.

During the 1970s and 1980s, process-product research focused on teacher competence mainly by investigating the effect of particular teacher's behavior on leaners' academic achievement. The next trend of studies on teacher quality highlighted how teacher's mental understanding and decision-making influenced how they taught in class (Calderhead, 1996). During the previous two decades, researchers continued to investigate the concept of teacher expertise, whose theoretical basis lies in cognitive psychology. Such researchers included Berliner (1994) and Leinhardt \& Greeno (1986). In the present article, a variety of characteristics and idiosyncrasies of exemplary teachers are identified, presented and analyzed. Contrary to investigations which emphasize on particular teacher-induced mediations so that learner's performance is enhanced, research on expertise emphasizes on the complicated and flexible mental functioning that triggers teachers' particular decisions on the spot (Berliner, 1994).

Almost no importance has been given to the principles employed to distinguish expert teachers in recent different academic investigations in spite of the prevalent employment of the phrase 'expert teacher'. Unambiguous guidelines were offered by Berliner (1994) for picking out expert teachers. Berliner is mostly cited by investigators in describing their sample selections. But a more precise investigation into how they made their selection shows much discrepancy in how those guidelines were comprehended or enacted. As reminded by Sternberg (1998), researchers employ the phrase 'gifted teacher', not having thought of its complexion. The definition of an expert teacher is thus further obscured.

This article seeks to present and criticize the selection criteria widely used by researchers for expert English language teachers. A number of methodological considerations added to the inspiration of carrying out the present research. As described by Nunnally and Bernstein (1994), the main obsessions of science are comprised of: 1. creating ways and instruments to size up constructs, along with 2. finding out the correlations of diverse measures of various constructs. Therefore, to validate constructs it is needed to specify the domain observables concerning that construct. In sample selection, if the specific features (selection criteria) are not identified and continuously employed then it is not evident what, or, for expert teachers, who, is actually being investigated in the body of related research. The varying use of expert selection markers, therefore, will have important effects on the implications of the results obtained from such 
investigations. In case we give into the divergences in detecting exemplary teachers, we are finally faced with a body of previous research whose informative value for pedagogical investigators and decision makers is restricted. So is its informative value concerning the quality of expertise in teaching and how it is developed in highly efficient teachers. As an instance, imagine study 1 contrasts novice teachers' pedagogical understandings and communications with distinguished, highly effective teachers through employing a number of aspects such as the length of working background, and subsequently contrasts the behavior of these identified teachers with that of the experts. These two investigations entail delving into teacher expertise, but the populations investigated might have been totally different. Experts in the first research could act as advanced beginners despite being recognized to be experts. No inferences concerning their teaching acts could be reliable because of the differences between the groups compared. We critically analyzed the steps followed to single out exemplary or the so-called expert teachers and categorized these selection criteria according to a review of expertise construct. The categorization we presented and our critical analysis illuminate researchers' decision-making in this realm and is investigated with reference to the relevant previous research on teacher quality.

Besides methodological concerns, there are several conceptual issues that lie beneath the requirement of a critical consideration of expert teachers' recognition. The existing standards of teachers in the U.S., presumably the most comprehensive standards worldwide, have been identified as an obstacle to the provision of efficient teaching (National Commission on Teaching and America's Future, 2003). Investigations focused on teacher expertise would possibly affect the ingenuity in teacher education, evaluation, or certification. As an instance, NBPTS has focused comprehensively on the related research on teacher expertise in devising standards of instruction (Bond, Smith, Baker, \& Hattie, 2000).

As for teacher's knowledge, investigators have shown subject-matter knowledge is essential for teachers to succeed but the amount of subject knowledge required and the most effective way to evaluate it is not obvious. Moreover, Berliner (1994) states that teachers' familiarity with learners and teaching procedures distinguishes experts and nonexperts. Similarly, Stough and Palmer (2003) contend that expert instructors of special education possess a complicated source of knowledge or competence which includes learner knowledge. Furthermore, such teachers utilized their knowledge adaptively so that they satisfy particular expectations of their pupils. Nevertheless, the extent to which the varying types of knowledge contribute to the identification of expert teachers is not yet clear-cut.

The critical analysis of the above-mentioned criteria in studies on teacher expertise would help investigators' perusal and judgment of existing body of research on expertise as well as developing further research within this realm. The majority of instructional investigators and scholars work independently from each other; and have not frequently studied particular constructs each as part of a meta-analytic research with a cooperative goal. Therefore, there rarely is a disciplined attempt to devise reliable ways to assess various constructs (Nunnally \& Bernstein, 1994). We propose that our article clarifies those domain observables associated with the construct of teacher expertise.

\section{EXPERTISE AS A CONSTRUCT}

Fundamental investigations of expertise in teaching are based on a plenty of research on the cognitive aspect of expertise. Such research in disciplines other than instruction found that the way experts think and act is completely divergent from non-experts. Expertise was found to require long of hours of hard practice in that realm (Berliner, 1994; Ericsson, 1996). Another issue reported was that the structure of expert knowledge is different from that of non-experts. The expert knowledge can be obtained in an effective way in the face of new problems (Berliner, 1994; Glaser \& Chi, 1988). Experts' cognitive attributes have been investigated in a wide array of fields such as chess, medical sciences, and physical education (Ericsson, 1996). Overall, research findings indicated that experts' intellectual features were regulated and coherent. So far, researchers have used a variety of decision rules, both implicit and explicit, to select and describe expert teachers. In the following first we deal with common criteria of identifying experts from novices including teachers. Next, we cast a look at the national standards of English language teachers in England and the U.S.

\section{CURRENT CRITERIA OF EXPERTISE IN TEACHING AND ELT}

\section{A. Length of Occupational Background or Deliberate Practice}

A highly prevalent criterion concerning how expertise is developed is one's experiential background, commonly thought of as years of working. According to Ericsson, Krampe, and Tesch-Romer (1993) the mere experience is not adequate; instead, deliberate practice in a specific realm is essential for the growth of expertise. These researchers describe deliberate practice as involvement in particular practices at a suitable difficulty level so that it equips the person with various chances of repeating those practices, along with useful feedback on executing those acts to sort out errors (Ericsson et al., 1993). One factor that is strictly related to experts' deliberate practice is the craving for excellence which experts show in their field. Therefore, experts appear to look for opportunities of deliberate practice in their filed.

In 1998, Sternberg proposed his model for the development of expertise which similarly highlighted the active role and practice of experts within a particular domain in order for their expertise to be developed. Despite the individual idiosyncrasies in the speed of achieving expertise and the degree of expertise achieved, this scholar argued that the key 
contributing factor of attaining expertise is one's goal-oriented immersion in the tasks within their domain of expertise. Such active involvement is accompanied by direct instruction as well as one's massive reflection and motivation to achieve expertise.

In the literature concerned with teaching and more specifically language teaching, it is common to view teachers with more than five years of experience considered as 'experienced' ones and even as 'experts' (used interchangeably). However, what appears to be critical is that these two notions i.e. experience and expertise are not necessarily correlated as revealed in later research or observations. The best relation which could be thought of was that the latter certainly included the former but vice versa was not necessarily true. Put it simpler, we could distinguish between expert and non-expert experienced teachers. What the latter implies, as elaborated by Tsui (2005), is that after many years of teaching, some teachers become complacent with their current practice and merely rely on their habits and routines developed throughout the years and slow down on further development of their knowledge and skills. In other words, they let their knowledge and skills become fossilized and outdated. Therefore, it seems that the length of teaching experience alone cannot be a reliable indicator of a teacher's expertise.

\section{B. Experts' Social Recognition or Group Membership}

Human expertise is described as, at least partly, a social construct (Agnew et al, 1997). A number of metaphors have been proposed for expertise by LaFrance (1997) one of which is the word courtship which means that it is the others who decide on who is called an expert and who is not. Those identified to be experts are not necessarily the most knowledgeable. They are perceived and recognized as experts by others in a group.

Another type of social recognition is to be a member of a well-recognized and credible group. Two levels of expertise are proposed here. Firstly, the entire experts are socially elected by a public community (the first plane). Such experts might as well be engaged in choosing colleagues to join their position. Besides that, a second plane of expertise is believed to exist. These experts acquire their position because of verifiable, observable practice-based criteria meeting strict scientific standards. Normative as well as criterion-based practical markers are employed to characterize expertise (to be explained later).

In Palmer et al.'s (2005) study, the most common means of an expert teacher's social recognition was the school principal's nomination. Nominations from other groups are also mentioned including other teachers, college personnel, school staff, etc. Teacher certification was also mentioned as an indicator of teaching expertise. Membership in educational organizations for instance as a mentor teacher, or supervisor were also mentioned in the literature. However, social or professional recognition have not been mentioned as the sole indicator of expert teachers in the literature. It can as well be criticized for its subjective and highly variable basis. As an instance, what is expected from a mentor teacher might differ from one educational context to another. Others' judgment could be influenced by a myriad of psychological or sociological factors which are hard to control or tell apart. That is, sometimes factors other than pedagogical skills inspire these so-called others' decisions (including colleagues, principal, etc.). Among such factors are previous acquaintance or friendship, appearance and the like. Therefore, it is hard to predict, based on what exactly, they recommend a particular person as an expert teacher. Even when asked, they themselves might find it difficult to mention all the factors involved in selecting a particular colleague as the expert.

\section{Rewards and Recommendations from School}

These are based on formative assessment of teachers' performance carried out by the school principal, research team or the district board. Sometimes it is in the form of awards being given (for example yearly) and sometimes in appointing the admired teachers to additional posts such as a teacher-group leader or a mentor teacher who assesses and comments on other colleagues' performance (Tsui, 2003; Tsui, 2005; Goodwyn, 2011). However, this criterion is very subjective indeed and needs to be considered with care since such awards and nominations are basically founded on other underlying criteria set by the school or district. In judging on the expertise of a teacher according to this criterion, we should first make sure of the validity of the more underlying criteria. Put it simply, when A attests to the credibility and value of $\mathrm{B}$, first we should be convinced of the credibility of $\mathrm{A}$ !

\section{Learners' Achievement}

The use of this criterion in judging on the expertise of teachers has been on the rise recently. However, beneath such criterion lies the assumption that there exists a linear causal relationship between teacher expertise and learner achievement. This is where the problem lies, as we are aware that there is a host of factors affecting students' performance, among which teacher's expertise is only one. These factors range from the socio-economic status of learners to the physical/contextual condition of the classroom (Tsui, 2003; Tsui, 2005; Goodwyn, 2011).

Another problem appears when teacher's expertise is based on learners' performance on the standardized tests. This means that their expertise is determined indirectly through the performance of their students. This is different from other domains where expertise is determined directly through the performance of the expert.

\section{E. Norm-based Performing Markers}

Investigating expertise is partially delving into the actions and behavior of those outperforming the average within a scope of human performance. As Ericsson (1996) puts it, those who repetitively overcome others in competitions are 
perceived as experts. According to normative criteria, in order to identify experts, they are necessarily compared to other participants. As for expert teachers, they are selected based on the quality of their action and behavior in a particular task compared to other colleagues or beginner teachers. Instances of such criteria were garrulous teachers identified by school managers for taking part in stimulated recall activities (for example Allen \& Casbergue, 1997) and the direct observation of classroom teaching by independent experts (e.g., Bromme \& Steinbring, 1994). Here, the judgment is highly dependent on the checklist which can vary from school to school and even from one observer to another within the same educational context. The lack of a consistent, valid and comprehensive basis of evaluation seems to be the major drawback along with the lack of reliability of the evaluation.

\section{F. Criterion-based Performing Markers}

Exemplary performance cannot be absolutely and uncontroversially defined. Criterion-based performing measures might encompass the recurrence, exactitude, as well as the time length of performing a task. One form of performancerelated criteria is called criterion-based indicators according to which the teacher's practice is compared to a preexisting standard. Instances include teachers who obtained the best scores by more than one supervisor on predetermined criteria (e.g., Copeland et al, 1994). These suffer from the same drawbacks as those of the previous two criteria. The most important problem lies in the quality of the criterion based on which teachers' performance is evaluated. Who determines those criteria? Are they global or local in nature? Are they culturally, socially or politically loaded or not? Who are the major decision makers? Is their own expertise already established? And a myriad of similar questions remain to be answered.

\section{NATIONAL STANDARDS}

Notions of competence have led on to the proliferation of standards produced to describe teaching as a series of levels of achievement the most developed of which is an advanced or excellent teacher. In a number of English speaking countries, national standards of teaching English have been proposed and the level of expertise has been defined by a number of attributes. The most comprehensive of these standards belong to England and the U.S.

In the U.S.A. there are two terms which are used to imply expertise in teaching, one is 'master teacher' and the other 'highly accomplished teacher'. The former is a designation given at the district level and usually follows from some professional development work. The latter is the nationally significant one established by the National Board for Professional Teaching Standards (NBPTS). This is now recognized as the most developed model in the world. The NBPTS is one of the only organizations to develop very detailed subject-specific standards (Goodwyn, 2011).

The current model in England is a developmental model of expertise the final stage of which is called an advanced skill teacher (AST). These are actually different terms for the same notion of an expert teacher of English. They truly attempt to act as a reliable, comprehensive and detailed illustration of the development of expertise. However, they suffer from particular drawbacks. Firstly, trying to encapsulate the complex notion of teaching expertise in a number of fixed, limited and static standards is far from the true nature of expertise. Secondly, there is a tension between autonomy and accountability and the use of standards. A real expert must be reasonably accountable but must also maintain a significant degree of autonomy and be able to exercise reasoned professional judgment. What degree of accountability is reasonable for teaching as an expert? Do differing degrees of accountability act as a developmental pressure on improving teaching or can they produce a compliance culture which limits creativity and nullifies expertise? These are challenging questions in relation to expert teaching.

\section{CONCLUSION}

As pinpointed in the introduction, the nature of expertise has long attracted the attention of researchers in the field of cognitive psychology. However, it has been relatively less explored until recently in relation to classroom teaching and even less so in the field of second and foreign language teaching. In the background attempts of setting and defining the criteria for teacher expertise, a multitude of diverse, incomprehensive and in some cases questionable attributes have been suggested which are mostly subjectively assessed and ascribed. Not only are they not able to characterize an expert teacher of English in separation, but also together they are still unable to account for the true construct of teacher expertise. Furthermore, they are mostly based on the comparison of the novice and the experts and hide the real quality of expert performance.

What is suggested in the present research is for scholars and researchers in ELT to narrow down the focus of their investigations on the notion of EFL/ESL teacher expertise and operationalize it through the development of a wellorganized and valid instrument. This instrument is supposed to act as a benchmark against which less successful teaching can be reliably compared and distinguish the expert from non-expert performance among English language teachers internationally. The prospective instrument is supposed to include the two major dimensions: teacher's knowledge and teacher's performance (behavior). The former must include teacher's subject matter knowledge, pedagogical content knowledge and curricular knowledge (Shulman, 1987). The latter is expected to include skills such as class management, decision making, problem solving, monitoring and so on. Each would have its own sub-skills. In determining exactly which issues are to be included in the framework (based on which the instrument is designed), 
attitudes of the following should be obtained: ELT academics, researchers, acknowledged experienced professionals and teacher educators. Subsequently, each category along with its sub-elements can be structured as a self-rating questionnaire in a likert type. It can be used as a checklist as well, but one the answers to which are quantitatively analyzable. Application of such instrument provides an operational definition for the construct of expertise in English language teaching. Currently the design of this instrument is being done by the researchers of the present study. However, we thought it would be wise first to draw attention to the essentiality of such an attempt. This article, in fact, tried to make the gap more visible and pave the way for the further steps of providing a well-structured, valid and comprehensive operational definition for an expert teacher of English in ELT. It should be acknowledged that similar attempts have already been made in other domains, as mentioned previously such as chess, medicine, law, etc. Therefore, its necessity and usefulness is already established in other disciplines. We believe it is time we began to define it in applied linguistics too. This article is privileged to be one of the pioneering steps along this path.

\section{ACKNOWLEDGEMENT}

The authors wish to express their thanks to Dr. Gholam Reza Kiany and Dr. Reza Ghaffar Samar for their helpful support and feedback all through this research.

\section{REFERENCES}

[1] Agnew, N.M., Ford, K.M., \& Hayes, P. J. (1997). Expertise in context: Personally constructed, socially selected, and realityrelevant? In P. J. Feltovich, K. M. Ford, \& R. R. Hoffman (Eds.), Expertise in context (pp. 219-244). Cambridge, MA: MIT Press.

[2] American Council on Education. (1999). To touch the future; transforming the way teachers are taught. Washington, DC: Author.

[3] Berliner, D. C. (1994). Expertise: The wonder of exemplary performances. In J. N. Mangieri \& C. C. Block (Eds.), Creating powerful thinking in teachers and students (pp. 161-186). Fort Worth, TX: Holt, Rinehart \& Winston.

[4] Bond, L., Smith, T., Baker, W. K., \& Hattie, J. A. (2000). The certification system of the National Board for Professional Teaching Standards: A construct and consequential validity study. Greenboro: University of North Carolina, Center for Education Research and Evaluation.

[5] Bromme, R., \& Steinbring, H. (1994). Interactive development of subject matter in the mathematics classroom. Educational Studies in Mathematics, 27, 217-248.

[6] Calderhead, J. (1996). Teachers: Beliefs and knowledge. In D. Berliner \& R. Calfee (Eds.), Handbook of educational psychology (pp. 709-725). New York: Macmillan.

[7] Copeland, W. D., Birmingham, C., DeMeulle, L., D’Emidio-Caston, J., \& Natal, D. (1994). Making meaning in classrooms: An investigation of cognitive processes in aspiring teachers, experienced teachers, and their peers. American Educational Research Journal, 31, 166-196.

[8] Dwyer, C., \& Stufflebeam, D. (1996). Teacher evaluation. In D. Berliner \& R. Calfee (Eds.), Handbook of educational psychology (pp. 765-786). New York: Macmillan.

[9] Education Trust. (2003). Telling the whole truth (or not) about highly qualified teachers. Washington, DC: The Education Trust.

[10] Ericsson, K. A. (1996). The acquisition of expert performance: An introduction to some of the issues. In K. A. Ericsson (Ed.), The road to excellence: The acquisition of expert performance in the arts, sciences, sports, and games (pp. 1-50). Hillsdale, NJ: Lawrence Erlbaum Associates, Inc.

[11] Ericsson, K. A., Krampe, R. T., \& Tesch-Romer, C. (1993). The role of deliberate practice in the acquisition of expert performance. Psychological Review, 100(3), 363-406.

[12] Goodwyn, A. (2011). The expert teacher of English. London and New York: Routledge.

[13] LaFrance, M. (1997). Metaphors for expertise: How knowledge engineers picture human expertise. In P. J. Feltovich, K. M. Ford, \& R. R. Hoffman (Eds.), Expertise in context. Cambridge, MA: MIT Press.

[14] Leinhardt, G. (1983). Novice and expert knowledge of individual student's achievement. Educational Psychologist, 18, 165179.

[15] Leinhardt, G., \& Greeno, J. G. (1986). The cognitive skill of teaching. Journal of Educational Psychology, 78, 75-95.

[16] National Commission on Teaching and America's Future. (2003) No dream denied: A pledge to America's children. Washington, DC: National Commission on Teaching and America's Future.

[17] Nunnally, J. C., \& Bernstein, I. H. (1994). Psychometric theory. New York: McGraw-Hill.

[18] Palmer, D. J., Stough, L. M.; Burdensky, T. K.; \& Gonzales, Jr. M. (2005). Identifying teacher expertise: an examination of researchers' decision making. Educational Psychologist, 40(1). 13-25.

[19] Shulman, L. S. (1987). Knowledge and teaching: Foundations of the new reform. Harvard Education Review, 57, 1-22.

[20] Sternberg, R. J. (1998). Abilities are forms of developing expertise. Educational Researcher, 27(3), 11-20.

[21] Stough, L. M.,\& Palmer, D. J. (2003). Special thinking in special settings: A qualitative study of expert special educators. The Journal of Special Education, 36(4), 206-222.

[22] Tsui, A. B. M. (2003). Understanding expertise in teaching: case studies of ESL teachers. Cambridge: Cambridge University Press.

[23] Tsui, A. B. M. (2005). Expertise in teaching: perspectives and issues. In Johnson, K. (ed.) Expertise in second language learning and teaching. New York: Palgrave Macmillan. 
Ramin Akbari holds a Ph.D. of TEFL from Isfahan State University. Currently, he is an assistant professor of ELT in Tarbiat Modares University of Tehran and also the head of the teacher quality control department of Safir Language Institute of Iran.

Elham Yazdanmehr is currently a Ph.D. candidate of TEFL at Tarbiat Modares University of Tehran, Iran. Her main areas of interest include teacher education and critical pedagogy. 